\title{
Quality and consumer properties of bread baked from mixture of rye and wheat flour using iodine-containing additives
}

\author{
E. V. Dulova*, M. Yu. Kiseleva, Yu. G. Nasyrova, S. Kuzmina, and N. Prazdnichkova \\ Samara State Agrarian University, Kinel 446442, Samara region, Russia
}

\begin{abstract}
Nowadays the state policy in the field of healthy nutrition of the population pays special attention to the development, production and sale of functional products with the purpose of preservation and promotion of health of the population, prevention of diseases, including those caused by defective and unbalanced nutrition of children and adults. The enrichment of bread with iodine is effective and safe, technologically feasible, has a minimal impact on the price of products. The bread production according to the experimental variants was carried out by the method of test laboratory baking, followed by the assessment by quality indicators according to generally accepted methods. Iodine additives were added during the mixing of the dough with liquid components. It was established that iodine-containing raw materials had an ambiguous effect on the overall baking evaluation of bread baked from wheat-rye flour with the addition of iodine-containing raw materials. With each stage of the technological process, a gradual decrease in the iodine content in all samples occurs due to the influence of various temperatures and mechanical stress. Bread with the addition of iodine casein after kneading contains 147.75 micrograms of iodine, after proofing - 126.64 micrograms, and after baking - 94.99 micrograms. During storage, a similar situation is observed, for example, after 24 hours of storage the bread with the addition of iodinedar contains $68.43 \mu \mathrm{g}$, and after 48 hours $-59.77 \mu \mathrm{g}$.
\end{abstract}

\section{Introduction}

The state of human health is determined by three components: genetics, lifestyle and nutrition. Food is one of the most important factors affecting the mental and physical development of a person, his professional performance, and, ultimately, his life expectancy.

In many countries, including Russia, the nutritional structure is not rational, as a result of which vitamin $\mathrm{C}$ deficiency and deficiency of B vitamins (carotene and vitamin E) is observed. The majority of the population receives an insufficient amount of iodine, calcium, iron, fluoride, fiber and other bio-regulators of vital processes with food.

Hormonal disorders associated with iodine deficiency lead to the disruption of nervous system, brain, genital and mammary glands of a person. The elimination of iodine deficiency is one of the highest priorities of the world community.

Mankind has been solving this problem for many decades, but it remains relevant still. It is explained by the fact that there is no comprehensive approach to the problem, and it is impossible to solve it by any single measure, for the reason that iodine must be supplied to human body constantly and in the required amount throughout his life [1,2].

Iodine is an essential component of thyroid hormones. It is unevenly distributed throughout the world, and currently more than a billion people live in areas with significant iodine deficiency. This article describes the optimal iodine nutrition, the effects of iodine deficiency, methods for its elimination and the current state of the world $[2,3]$.

The cheapest and most popular way to solve the problem of iodine deficiency is the use of iodized salt. This method is widely used all over the world. The World Health Organization has been promoting salt iodization since the seventies of the last century.

The disadvantage is the impossibility of a strict dosage of iodine and, accordingly, possible complications from the thyroid gland caused by an overdose of iodine.

In most countries, the best strategy to combat iodine deficiency is to carefully monitor salt iodization. The studies to develop food products with the addition of iodized kitchen salt are being conducted [4-6].

In the United States, the problem of iodine deficiency is solved mainly through dairy products [7]. Many Russian scientists are involved in the problem of enrichment of food products with iodine-containing raw materials [8-10].

In order to solve the problem of the prevention of iodine deficiency among a healthy population, it is advisable and necessary to expand the range of iodinecontaining products for everyday consumption.

Bread is such a best representative and there are several technologies for its iodization due to iodinecontaining raw materials.

*Corresponding author: dulova_e@mail.ru 
Research purpose is to determine the effect of iodine-containing raw materials and additives on the iodine content in the tin formed bread from a mixture of rye and wheat flour.

\section{Research tasks:}

- To analyze iodine-containing raw materials and additives for therapeutic purposes.

- To develop the formulation of rye-wheat bread for therapeutic purposes;

- To determine the quality of iodized rye-wheat bread by organoleptic and physico-chemical indicators;
- To determine the safety of iodine during processing and storage of rye-wheat bread, depending on the use of iodine-containing raw materials and additives.

\section{Materials and methods}

Rye-wheat for therapeutic purposes bread using iodinecontaining raw materials was prepared according to the recipe indicated in Table 1.

Table 1. Recipe of rye-wheat bread for therapeutic purposes

\begin{tabular}{|l|c|c|c|c|c|}
\hline \multicolumn{1}{|c|}{ Raw material item } & \multicolumn{5}{c|}{ Amount of raw material, $\mathrm{kg}$} \\
\hline Wheat flour & 50.0 & 50.0 & 50.0 & 50.0 & 50.0 \\
\hline Rye flour & 50.0 & 50.0 & 50.0 & 50.0 & 50.0 \\
\hline Yeast & 2.5 & 2.5 & 2.5 & 2.5 & 2.5 \\
\hline Salt & 1.5 & 1.5 & 1,5 & 1.5 & 1.5 \\
\hline Iodine additives: & & & & & \\
\hline iodine casein & - & 0.0005 & - & - & - \\
\hline iodinedar & - & - & 0.0018 & - & - \\
\hline iodized salt & - & - & - & 1.0 & - \\
\hline seaweed & - & - & - & - & 1.3 \\
\hline
\end{tabular}

In the experiments, a method of dough mixing on liquid dough was used. For baking, wheat and rye flour was used, which according to organoleptic and physicochemical quality indicators corresponded to the requirements of Russian standards for these products. The bread production according to the experimental variants was carried out by the method of test laboratory baking, followed by the assessment by quality indicators according to generally accepted methods. Iodine additives were added during the dough mixing with liquid components.

Casein is a protein rich in amino acids: tyrosine, histidine, etc., which form strong compounds with iodine. Iodine casein is used for iodization of bread, dairy products, as a part of vitamins and mineral complexes.

The receipt of amino acids from digestive tract into liver is accompanied by the elimination of iodine from them under the action of an enzyme (deiodinase). The activity of this enzyme is directly dependent on the degree of iodine deficiency and the functional state of the thyroid gland. The excessive amounts of iodinated amino acids (iodotyrosine), turning into glucuronides, leave a body. Thus, human body has a physiological mechanism for adjusting the amount of iodized protein necessary for it [8].

Original iodine-containing raw materials "Iodinedar", intended for the enrichment of bread, bakery and crackers. In their structure they do not differ from the natural compounds of iodine contained in seafood, milk, meat, eggs. This is a physiological and effective source of non-hormonal organic iodine, which allows optimal elimination of iodine deficiency in humans.

Seaweed (kelp) contains a lot of iodine necessary for humans, amino acids, vitamins and microelements, including those that can not be found in any other plant.
This is a ready natural, balanced complex containing: about 40 micro and macro elements in combination with organic substances; iodine (up to $3 \%$ ), bromine, manganese, cobalt, zinc, magnesium, iron, potassium, sodium, sulfur, phosphorus, nitrogen, etc.; alginic acid and its salts (up to 25\%); kelp polysaccharides (up to $21 \%$ ); vitamins: A, B1, B2, B12, C, D, E, pantothenic and folic acid; mannitol (20-25\%); protein substances (up to $9 \%$ ); L-fructose (up to $4 \%$ ).

Iodized salt - in recent years, it is mainly produced by adding a fixed amount of potassium iodate to edible kitchen salt.

\section{Results}

The digestibility of bread is largely associated with its organoleptic characteristics, primarily such as taste, aroma, crumb condition, which together form the concept of bread quality. The quality of bread is determined by the composition and properties of the ingredients included in its composition, as well as by the processes that take place in the dough during its maturation and baking of dough pieces.

During the study, such organoleptic indicators as the state of the surface of bread, the color and condition of crust, the absence or presence of peeling of crust from crumb, the shape of a product, the state of crumb (freshness, bakedness, absence of signs of dough not being mixed, pore size and uniformity, and crumb elasticity, smell, taste) were determined and the total baking score as the average value from these indicators was calculated.

Iodine-containing raw materials had an ambiguous effect on the overall baking evaluation of bread baked from wheat-rye flour with the addition of iodinecontaining raw materials. 
The highest score was given to the sample with the addition of iodine casein -4.4 points; the average score was given to iodinedar and iodized salt -4.0 and 4.1 points, respectively.

The sample with seaweed received the lowest score 3.7 points; this bread has a less pleasant appearance and taste compared to other samples.

The physico-chemical indicators of the quality of bread were also determined. They are presented in Table 2.

Table 2. Physico-chemical quality indicators of rye-wheat bread with the addition of iodine-containing raw materials

\begin{tabular}{|l|c|c|c|}
\hline \multicolumn{1}{|c|}{ Experimental variants } & $\begin{array}{c}\text { Moisture content } \\
\text { of crumb, } \%\end{array}$ & $\begin{array}{c}\text { Porosity of } \\
\text { crumb, \% }\end{array}$ & $\begin{array}{c}\text { Acid content of } \\
\text { crumb, } \mathrm{T}^{\circ}\end{array}$ \\
\hline rye flour 50\% + wheat flour 50\% & 40.8 & 62.2 & 4.4 \\
\hline rye flour 50\% + wheat flour 50\% + iodine casein & 39.0 & 64.4 & 5.4 \\
\hline rye flour 50\% + wheat flour 50\% + iodinedar & 39.2 & 69.4 & 5.5 \\
\hline rye flour 50\% + wheat flour 50\% + iodized salt & 38.6 & 60.5 & 6.6 \\
\hline rye flour 50\% + wheat flour 50\% + seaweed & 39.7 & 60.5 & 6.0 \\
\hline
\end{tabular}

As it can be seen from the presented data, the maximum moisture content of the crumb is observed in the control sample - 40.8\%; minimal - in bread with iodized salt $38.6 \%$.

The leader in porosity is a sample with iodinedar $69.4 \%$, and the lowest value of porosity is observed in samples with seaweed and iodized salt - 60.5\%. The highest acid content of the crumb is in bread with the addition of iodized salt $-6.6 \mathrm{~T}^{\circ}$, the lowest acidity is 4.4 $\mathrm{T}^{\circ}$ in the control sample.

During storage, bread changes its quality indicators. Bread firming is caused mainly by the change in the structure of starch during storage of bread. The starch gelled during baking, in the course of time, releases the moisture absorbed by it and returns to its previous state, which is typical for flour starch.

The authors studied the quality indicators (moisture and acid contents, porosity) of bread after baking, 24, 48 and 72 hours of storage (Table 2).

During the storage of these samples of bread, it was noted that with the increase in the storage period, the humidity of the products decreased by $0.05 \quad \ldots .9 \%$ depending on the options of the studied formulations and the period of storage, and on the third day of storage the humidity was the lowest.

Table 3. Physico-chemical quality indicators of rye-wheat bread with the addition of iodine-containing raw materials depending on the period of storage

\begin{tabular}{|c|c|c|c|}
\hline Experimental variants & $\begin{array}{c}\text { Moisture content } \\
\text { of crumb, } \%\end{array}$ & $\begin{array}{l}\text { Porosity of } \\
\text { crumb, } \%\end{array}$ & $\begin{array}{c}\text { Acid content of } \\
\text { crumb, } \mathrm{T}^{\circ}\end{array}$ \\
\hline \multicolumn{4}{|c|}{24 hours of storage } \\
\hline rye flour $50 \%+$ wheat flour $50 \%$ & 38.70 & 60.24 & 5.00 \\
\hline rye flour $50 \%+$ wheat flour $50 \%+$ iodine casein & 37.50 & 63.00 & 6.20 \\
\hline rye flour $50 \%+$ wheat flour $50 \%+$ iodinedar & 36.83 & 60.42 & 6.60 \\
\hline rye flour $50 \%+$ wheat flour $50 \%+$ iodized salt & 38.64 & 68.28 & 5.20 \\
\hline rye flour $50 \%+$ wheat flour $50 \%+$ seaweed & 37.23 & 59.63 & 5.40 \\
\hline \multicolumn{4}{|c|}{48 hours of storage } \\
\hline rye flour $50 \%+$ wheat flour $50 \%$ & 35.68 & 58.62 & 5.00 \\
\hline rye flour $50 \%+$ wheat flour $50 \%+$ iodine casein & 36.12 & 60.58 & 6.20 \\
\hline rye flour $50 \%+$ wheat flour $50 \%+$ iodinedar & 36.29 & 54.24 & 6.00 \\
\hline rye flour $50 \%+$ wheat flour $50 \%+$ iodized salt & 34.91 & 62.82 & 5.60 \\
\hline rye flour $50 \%+$ wheat flour $50 \%+$ seaweed & 37.18 & 53.14 & 6.50 \\
\hline \multicolumn{4}{|c|}{72 hours of storage } \\
\hline rye flour $50 \%+$ wheat flour $50 \%$ & 28.87 & 51.17 & 5.80 \\
\hline rye flour $50 \%+$ wheat flour $50 \%+$ iodine casein & 29.45 & 57.58 & 6.60 \\
\hline rye flour $50 \%+$ wheat flour $50 \%+$ iodinedar & 28.74 & 57.67 & 5.90 \\
\hline rye flour $50 \%+$ wheat flour $50 \%+$ iodized salt & 25.91 & 48.64 & 6.20 \\
\hline rye flour $50 \%+$ wheat flour $50 \%+$ seaweed & 31.50 & 55.62 & 7.20 \\
\hline
\end{tabular}

The porosity of bread is directly dependent on moisture: i.e. with the decrease in moisture, the decrease in the porosity of crumb was noted.
For example, after 24 hours of storage, the moisture content of bread with the addition of iodine casein was $37.50 \%$, and the porosity was $63 \%$; after 48 hours moisture decreased to $36.12 \%$ and porosity to $60.58 \%$; 
after 72 hours $-29.45 \%$ and $57.58 \%$, respectively. This dependence is also traced in case of other samples.

The safety of iodine during the technological processing is one of the most important enrichment criteria, confirming or refuting the feasibility and effectiveness of this measure.

As a result of the experiment, the authors determined the iodine content in bread with the addition of various iodine-containing raw materials at various stages of the technological process and during storage (Table 4).
As it can be seen from this Table with each step of the process there is a gradual decrease in iodine content in all samples due to the influence of various temperatures and mechanical stress. For example, it contains 147.75 micrograms of iodine in a sample with iodine casein, after kneading, after proofing it contains 126.64 micrograms, and after baking - 94.99 micrograms.

During storage, a similar situation is observed, for example, after 24 hours of storage, iodinedar contains $68.43 \mu \mathrm{g}$ in the sample, $59.77 \mu \mathrm{g}$ and after 48 hours.

Table 3. Iodine content in rye-wheat bread using iodine-containing raw materials at the stages of the technological process and during storage

\begin{tabular}{|l|c|c|c|c|c|c|}
\hline \multicolumn{2}{|c|}{ Experimental variants } & \multicolumn{5}{|c|}{ Iodine content in technological stages, mcg } \\
\cline { 2 - 7 } & $\begin{array}{c}\text { Raw } \\
\text { material }\end{array}$ & Mixing & Proofing & Baking & $\begin{array}{c}24 \text { hours } \\
\text { of storage }\end{array}$ & $\begin{array}{c}48 \text { hours } \\
\text { of storage }\end{array}$ \\
\hline rye flour 50\% + wheat flour 50\% & 66.0 & 62.32 & 58.50 & 44.22 & 40.32 & 37.46 \\
\hline $\begin{array}{l}\text { rye flour 50\% + wheat flour 50\% + iodine } \\
\text { casein }\end{array}$ & 156.00 & 147.75 & 126.64 & 94.99 & 79.15 & 63.32 \\
\hline $\begin{array}{l}\text { rye flour 50\% + wheat flour 50\% + } \\
\text { iodinedar }\end{array}$ & 160.50 & 149.57 & 125.48 & 91.62 & 68.43 & 59.77 \\
\hline $\begin{array}{l}\text { rye flour 50\% + wheat flour 50\% + iodized } \\
\text { salt }\end{array}$ & 121.00 & 98.94 & 77.86 & 68.60 & 52.40 & 40.22 \\
\hline $\begin{array}{l}\text { rye flour 50\% + wheat flour 50\% + } \\
\text { seaweed }\end{array}$ & 145.00 & 125.63 & 94.90 & 84.43 & 77.53 & 60.16 \\
\hline
\end{tabular}

According to the results of the studies, it is noted that the maximum content of iodine is contained and stored in bread with iodine casein $(63.32 \mu \mathrm{g})$, the minimum content is in the control sample $(37.46 \mu \mathrm{g})$ throughout the entire process and storage.

Thus, iodine casein is recognized as the most promising iodine carrier for bakery production; it provides the greatest preservation of iodine in finished products.

\section{Discussion}

The use of iodine-containing additives in bakery production does not affect the technology of production of bakery products, does not require the cost of restructuring production. After dissolving in water, iodized protein is introduced into the aqueous phase by mixing the dough, thereby achieving a uniform distribution of iodized protein in a product.

The studies have showed that the introduction of iodine-containing additives had a positive effect on the organoleptic indicators of bread quality. At the same time, the introduction of various additives had an ambiguous effect on such indicators as bread porosity, moisture and acid content.

The iodine content in rye-wheat bread using iodinecontaining raw materials at the stages of the technological process and during storage varies in different versions of the experiment and there is a tendency to its decrease.

The maximum iodine content in rye-wheat bread using iodine-containing raw materials was noted when iodinedar was added, however, the losses of this element at the stages of the technological process were also large after baking, and after 72 hours of storage, the maximum iodine content was noted on the experiment with the addition of the iodine casein protein supplement.

This bread can be attributed to the group of therapeutic products that contribute to the promotion of human health.

\section{Conclusion}

The use of iodine-containing additives in the production of bakery products is relevant both in the scientific and industrial fields, since the problem of iodine deficiency in the world and the Middle Volga region, in particular, has not been completely solved.

The introduction of iodine-containing additives has a positive effect on the taste characteristics of bread. The production according to organoleptic and physicochemical quality indicators meets the requirements of national standards.

In the production of rye-wheat bread, the authors recommend using the iodine-containing additive iodine casein to produce bread with therapeutic properties.

\section{References}

1. P. Taylor, O, Okosieme, J. H. Lazarus Lakdasa, D.K.E. Premawardhana, Encyclopedia of Endocrine Diseases (Second Edition) vol. 4, 512-523 (2018)

2. Reference Module in Biomedical Sciences Encyclopedia of Human Nutrition (Third Edition) 28-32 (2013) 
3. P. Laurberg, Iodine intake as a determinant of thyroid disorders in populations Best Practice \& Research Clinical Endocrinology \& Metabolism 24(1), 13 (February 2010)

4. T. H. Tulchinsky, Endemic Goiter and Elimination of Iodine Deficiency Disorders Case Studies in Public Health Chapter 10, 201-225 (2018)

5. M. Greisab, L. Seppäa, Impact of iodized table salt on the sensory characteristics of bread, sausage and pickle LWT 93, 606-612 (July 2018)

6. C. Thoma, J. Seal, D. Mackerras, A. Hunt, Flour and Breads and their Fortification in Health and Disease Prevention. Chapter 26 - Iodine Fortification of Bread: Experiences from Australia and New Zealand 281-291 (2011)

7. K. A. Vance, A. Makhmudov, R. L. Jones, K. L. Caldwell, Nutrients in Dairy and their Implications on Health and Disease. Chapter 11 - Dairy's
Inadvertent Contribution to Sustaining Optimal Iodine Nutrition 139-147 (2017)

8. S.I. Okhotnikov, The iodine enrichment of cheeses through the introduction of kelp Bulletin of Mari State University. Series: Agricultural Sciences. Economic sciences 2(10), 39-44 (2017)

9. M.I. Dulov, E.V. Krutyaeva, The use of iodinecontaining raw materials and additives in the production of bread from wheat flour in Agricultural science, a coll. of sci. papers dedicated to the $90^{\text {th }}$ anniversary of the Samara State Agricultural Academy 225-236 (Samara, Samara State Agricultural Academy, 2010)

10. E. Yu. Pashkova, E.V. Dulova, Consumer properties and competitiveness of bread from wheat flour of the highest grade with the use of iodine-containing raw materials in Materials of the int. sci. and pract. Conf. "Quality and safety of goods: from production to consumption” 353-358 (2019) 